\title{
Intravenous zanamivir for influenza myocarditis and enteral malabsorption
}

\author{
Fritz-Patrick Jahns ${ }^{1}$, Nawfel Ben-Hamouda ${ }^{1 *} \mathbb{D}$, Matthias Kirsch² ${ }^{2}$ Aurélien Roumy ${ }^{2}$ and Lucas Liaudet ${ }^{1}$
}

Keywords: Influenza, Myocarditis, Drug malabsorption, Extracorporeal life support

Acute myocarditis is an uncommon complication of influenza with a high mortality [1]. Early therapy with neuraminidase inhibitors (NI) is recommended in patients hospitalized for influenza, notably those with myocarditis. Oral oseltamivir is generally used as the first line NI therapy, whereas parenteral zanamivir and peramivir represent alternatives in selected patients who might not respond to oseltamivir, as may occur in conditions of gut failure and defective enteral drug absorption [2, 3]. We present two patients with influenza myocarditis complicated by enteral drug malabsorption, who received early intravenous zanamivir therapy with excellent clinical outcomes.

Patient 1 is a 49-year old woman, admitted with hypotension $(71 / 47 \mathrm{mmHg}$ ), high hsTroponin $\mathrm{T}$ (up to $1570 \mathrm{ng} / \mathrm{l}$ ), severe cardiac dysfunction (left ventricular ejection fraction (LVEF) of 20\%), and positive naso-pharyngeal swabs for influenza $B$. Patient 2 is a 30 -year old woman admitted with hypotension $(82 / 54 \mathrm{mmHg})$, severe cardiac dysfunction (LVEF of 15\%), elevated hsTroponin $\mathrm{T}$ (up to $3643 \mathrm{ng} / \mathrm{l}$ ), and positive swabs for influenza A. Both patients received oral oseltamivir $(300 \mathrm{mg}$ daily) and intravenous catecholamines (Fig. 1). In both, extracorporeal life support (ECLS) was started at day 2 for refractory cardiogenic shock. Given clinical deterioration, enteral drug absorption was assessed at day 4 for patient 1 and day 2 for patient 2 by a paracetamol absorption test [4], which measures sequential plasma paracetamol levels after enteral loading (via nasogastric tube) with $1000 \mathrm{mg}$ paracetamol. A marked impairment of enteral drug absorption was identified in both patients, leading to a switch from oral oseltamivir to parenteral zanamivir (patient 1, $600 \mathrm{mg}$ daily, adapted to renal function, from days 5 to 15 ; patient 2, $1200 \mathrm{mg}$ daily, from days 2 to 12). In the following days, catecholamines were steadily reduced, LVEF progressively improved, and ECLS was weaned (patient 1, day 12; patient 2, day 10 ). At ICU discharge, LVEF was $55 \%$ and $45 \%$, respectively.

In these two patients with influenza myocarditis and refractory cardiogenic shock, the rapid identification of poor drug absorption using a simple paracetamol absorption test allowed the early introduction of parenteral zanamivir instead of oral oseltamivir, with excellent clinical outcomes. Since drug malabsorption is frequent in critically ill

\footnotetext{
* Correspondence: nawfel.ben-hamouda@chuv.ch

${ }^{1}$ Department of Intensive Care Medicine and Burns, Lausanne University

Hospital Medical Center, CHUV, 1011 Lausanne, Switzerland

Full list of author information is available at the end of the article
} 


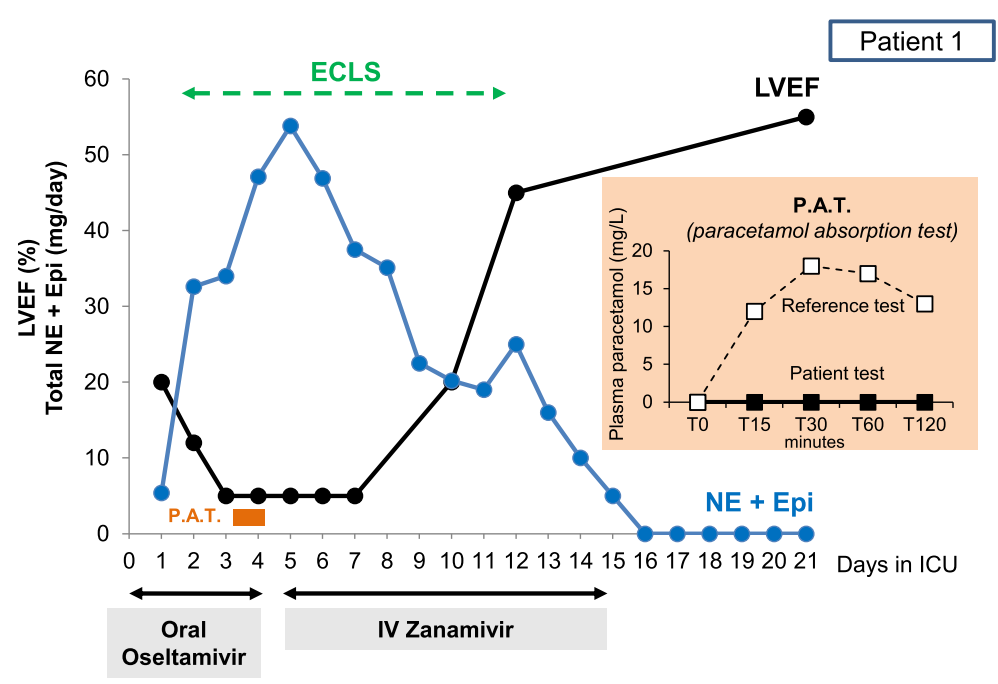

Patient 2

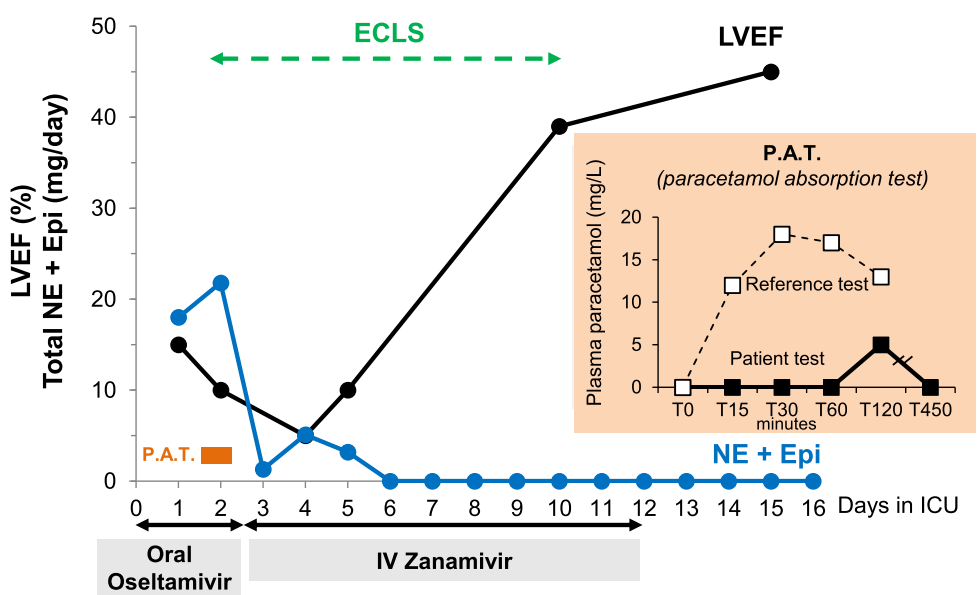

Fig. 1 Time-course of LVEF, catecholamines, and ECLS in two patients with fulminant influenza myocarditis. LVEF rapidly increased, allowing weaning of norepinephrine (NE), epinephrine (Epi), and extracorporeal life support (ECLS), after switching from oral oseltamivir to intravenous (IV) zanamivir, following a paracetamol absorption test (P.A.T.) showing enteral drug malabsorption (insert). The reference values for the test were obtained from [4]

patients with circulatory shock [5], we propose that a paracetamol pharmacokinetic study be performed early in patients with influenza myocarditis and cardiogenic shock to avoid any delay in the administration of parenteral therapy if enteral drug malabsorption is demonstrated.

\section{Acknowledgements}

None.

\section{Funding}

None.

\section{Availability of data and materials}

The datasets used during the current study are available from the corresponding author on reasonable request.

\section{Authors' contributions}

FPJ, data collection and analysis and writing the manuscript. NBH, data collection and analysis, writing the manuscript, and submission. MK, data collection and analysis and writing the manuscript. AR, data collection and analysis and writing the manuscript. LL, data collection and analysis and writing the manuscript and final revision. All authors read and approved the final manuscript.

Ethics approval and consent to participate Retrospective collection of data. Standard of care.

Consent for publication

Not applicable.

\section{Competing interests}

The authors declare that they have no competing interests.

\section{Publisher's Note}

Springer Nature remains neutral with regard to jurisdictional claims in published maps and institutional affiliations.

\section{Author details}

'Department of Intensive Care Medicine and Burns, Lausanne University Hospital Medical Center, CHUV, 1011 Lausanne, Switzerland. ${ }^{2}$ Department of 
Cardiovascular Surgery, Lausanne University Hospital Medical Center, 1011 Lausanne, Switzerland.

Received: 26 October 2018 Accepted: 15 November 2018

Published online: 04 December 2018

\section{References}

1. Ukimura A, Satomi H, Ooi Y, Kanzaki Y. Myocarditis associated with influenza A H1N1pdm2009. Influenza Res Treat. 2012;2012:351979.

2. Marty FM, Vidal-Puigserver J, Clark C, Gupta SK, Merino E, Garot D, et al. Intravenous zanamivir or oral oseltamivir for hospitalised patients with influenza: an international, randomised, double-blind, double-dummy, phase 3 trial. Lancet Respir Med. 2017;5:135-46.

3. Marty FM, Man CY, van der Horst C, Francois B, Garot D, Mánez R, et al. Safety and pharmacokinetics of intravenous zanamivir treatment in hospitalized adults with influenza: an open-label, multicenter, single-arm, phase II study. J Infect Dis. 2014;209:542-50.

4. Berger MM, Berger-Gryllaki M, Wiesel PH, Revelly JP, Hurni M, Cayeux C, et al. Intestinal absorption in patients after cardiac surgery. Crit Care Med. 2000;28:2217-23.

5. Roberts DJ, Hall RI. Drug absorption, distribution, metabolism and excretion considerations in critically ill adults. Expert Opin Drug Metab Toxicol. 2013;9:1067-84. 